**Graduando em Direito pelo Centro Universitário Adventista de São Paulo (UNASP). E-mail: lucasmesquita97@yahoo.com.br

**Professor do Centro Universitário Adventista de São Paulo (UNASP). Pós-doutor pela Università degli studi di Roma e Doutor pela PUC-SP. Mestre e graduado em Direito pela Universidade Metodista de Pircacicaba. E-mail: lucasmesquita97@yahoo.com.br

\section{Direito Sem Lei: um Modo-de-Ser do Ser Humano}

LAW Without RUles: A Way of BeING FOR the Human BEING

\section{Lucas Daniel Vieira Mesquita* Alessandro Jacomini**}

Como citar: MESQUITA, Lucas Daniel Vieira; JACOMINI, Alessandro. Direito sem lei: um modo-de-ser do ser humano. Revista do Direito Público, Londrina, v. 15, n. 1, p. 85-99, abr. 2020. DOI: $10.5433 / 24157-108104-1.2020 \mathrm{v} 15 \mathrm{n} 1 \mathrm{p}$. 85. ISSN: $1980-511 \mathrm{X}$

Resumo: $O$ presente artigo tem como objetivo ressaltar a possibilidade de um direito sem lei, fazendo considerações por meio da análise fenomenológica. Nesse sentido, inicialmente, trata-se da ideia, com uma observação crítica ao perigo e ao cuidado. Após isso, contempla-se, no pensamento pré-socrático e de Martin Heidegger, o estudo do ente-ser e da verdadeliberdade em relação à abertura do ser. Em outro plano, adentrase na pesquisa do círculo hermenêutico e da linguagem, sendo feito um empenho em busca de outras perspectivas do direito, destacando possibilidades distintas da justiça positivista, a qual limita os juristas contemporâneos.

Palavras-chave: Direito. Heidegger. Justiça. Lei. Ser.

Abstract: This scientific article highlights the possibility of law without rules or norms from a phenomenological model. In this sense, this paper analyzes it with critical observations of the dangers that it may present. In addition, this study explores "entity-being" and "truth-freedom" in relation to the individual from the context of pre-Socratic thought and of Martin Heidegger written works. On another level, this research explores the many intricacies of language in order to explore other perspectives of law, highlighting distinct possibilities of positivist justice, which limits contemporary jurists.

Keywords: Right. Heidegger. Justice. Law. Being. 


\section{INTRODUÇÃO}

O trabalho se atém às análises fenomenológicas, com a finalidade de se pensar em um olhar jurídico diferente da idealizada no Brasil e no Ocidente. O olhar citado é baseado no círculo hermenêutico e com fulcro no pensamento originário.

Em momento oportuno, é feita uma crítica ao sistema jurídico que despreza o ser. Também, são postas algumas premissas em relação ao pensamento meditante, com destaque ao pensamento pré-socrático e os seus desdobramentos característicos.

A filosofia de Martin Heidegger é utilizada em todo o trabalho. Nesse sentido, a verdade e a liberdade, como pertencentes ao pensamento citado, são abordadas com relação à abertura do ser. Todas as pontuações são acopladas ao direito, conectadas à linguagem e ao homem enquanto "exsistente", possibilitando, assim, um direito sem lei. Neste sentido, faz-se a seguinte indagação: Em um sistema que se prende em ideias (leis), seria possível a liberdade de direitos do ser humano?

Sequencialmente, analisam-se a ideia, as proposições do pensamento meditante, a questão ente-ser, a abertura do ser, o método fenomenológico, as percepções relacionadas ao direito e, por fim, uma maneira diferente do habitual de pensar a Justiça, baseando-se nas abordagens filosóficas arroladas.

Em qualquer trabalho científico, a metodologia é fundamental para sua elaboração, porque, de modo geral, é a explicação minuciosa de toda ação desenvolvida a fim de se chegar a uma consideração final. A natureza desse trabalho é classificada como analítica descritiva, pois se fundamenta em outros trabalhos já existentes, fazendo apenas interligações entre ideias de vários doutrinadores, doutores e professores.

Quanto à fonte de dados, a pesquisa é classificada como sendo bibliográfica, pois se baseia em fontes secundárias, tais como livros, artigos e periódicos. Quanto ao seu teor, é descrita como pesquisa qualitativa, pois não lida com dados numéricos, mas com o aprofundamento da compreensão de aspecto relacionado ao ser humano.

O presente trabalho concentra-se na seguinte problemática: É possível um direito sem lei? Contudo, objetiva-se, de maneira mais específica, atentar-se aos direitos das pessoas, prescritos em legislações, e aos direitos humanos, a partir do próprio ser humano, possibilitando refletir a respeito de um direito com lei em comparação a um sem lei.

\section{IDEIA}

Ao analisar uma determinada coisa, conclui-se que ela é aquilo que pensa dela. Mas isso é um equívoco. A coisa pensada é o objeto criado como imagem, é uma representação do objeto. A coisa é o que ela é, não a ideia que se tem dela. Este pensamento se conecta com a posição dos operadores ao analisar determinada coisa, atribuindo determinadas premissas como verdades, sendo que não "é" a coisa, e sim a fotografia da coisa, ou seja, a ideia sobre ela. Contudo, essa realidade é perigosa e merece cuidado. 
O pensar representativo só toma o existente como objético - ou seja, o ente só "é", quanto está fora do homem, mas, ao mesmo tempo, apreendido pelo seu pensar calculador -, então o mundo, tomado como a totalidade dos entes, se transforma em imagem. Esta é muito mais que reprodução, quadro ou cópia (MICHELAZZO, 1999, p. 61).

A maneira de pensar mudou muito com o passar do tempo. $\mathrm{O}$ idealismo platônico ganhou espaço porque o homem faz o que acha ideal. $\mathrm{O}$ homem se sente o centro do mundo e é por isso que a maioria das pessoas se identificam com tal pensamento. $O$ entendimento sobre humanismo, por exemplo, foi modificado. Ele busca os direitos humanos? Não, busca apenas as ideias sobre humanismo. Nesse contexto, ainda, as ideias superficiais são um perigo. Esse antropocentrismo está modificando essências e vem sendo aceito devido, simplesmente, à falta de reflexão a seu respeito.

Um conceito que se destaca no pensamento de Platão é paidéia. Michelazzo (1999, p. 44) afirma que, na visão de Heidegger, a mencionada palavra tem o significado de "acostumar", "adaptar" e "familiarizar", referindo-se ao empenho e esforço do homem. Entretanto, paidéia não ostenta uma tradução específica, aproximando-se, porém, de "formação" (bildung). Pode-se dizer, então, que é o ato orientador que marca o aceitar da coisa conforme uma visão ou retrato (espelho). Contudo, a ideia formada ao ver a coisa se torna o ponto destacável neste aspecto apresentado.

As coisas devem ser vistas com cuidado pelo homem, sem esquecer-se da essência delas. Suas características, então presentes como modos-de-ser, têm sido abandonadas. Jacomini (2012, p. 104) diz que "o problema do ser é um problema de ser, ou seja, existencial". Nesse aspecto, destaca-se o Dasein (ser-aí) como "um fluxo de possibilidades" a partir do "cuidado" no qual ele habita. O cuidado possibilita ao homem apreender o Dasein em seus êxtases temporais (presente, passado e futuro). Assim, o "homem existe cuidando de seu existir, cuidando de existir." (JACOMINI, 2012, p. 106).

É importante destacar aquilo que é existente/mostrável e aquilo que é oculto, ambos num processo de ocultação e desocultação do ser. A ideia é apenas uma representação que se tem do objeto, referindo-se somente ao ente e não ao ser. Já com o "cuidado", o indivíduo é remetido ao ser, desocultando-o. O equívoco da interpretação do ser como ideia tem provocado consequências fundamentais nesta questão do pensamento.

A aparência se viu declarada simples aparência e assim rebaixada. Concomitantemente o Ser se desloca, como idéa, para um lugar supra-sensível. O hiato, chorismos, se abriu entre o ente apenas aparente aqui embaixo e o Ser real em algum lugar lá em cima (HEIDEGGER, 1969, p. 132).

Neste sentido, as escolhas são modeladoras, sendo de suma importante a atenção diante de qualquer possibilidade, inclusive no âmbito jurídico, na "criação" de uma lei, por exemplo. Questiona-se “o que é a lei?" e tem-se como resposta "a lei é uma ideia”. Mas, para que ela tenha 
validade, os legitimados devem seguir alguns procedimentos de positivação. Assim, a realidade será moldada e os indivíduos terão seus direitos. Entretanto, seria correto permitir que o real se modifique por meio dessa ideia? Existe o direito apenas se positivado, ou seja, na lei?

A formatação, a idealização ou a entificação daquilo que é, acaba por moldar e limitar a abertura própria do ser. As coisas não são vistas como elas são, em seus modos-de-ser, mas apenas em sua representação ideal. A imagem da coisa trilha a ideia de benefício próprio, como ajuste do ego. Quanto às pessoas, Jacomini (2012, p. 24) afirma que a "massificação do homem se caracteriza de tal forma que, estando ele fora dos padrões estabelecidos, tem já a impressão de irrealidade, assim como um objeto em seu próprio mundo".

A definição de tudo, em uma análise platônica, está no homem, e não como os pré-socráticos pensavam, na própria coisa. Quando se trata de ideia, deve-se ter cautela porque a ideia não tem limite e, assim, é possível tomar conclusões de coisas que não são reais. No direito, isso acontece corriqueiramente. Há uma formatação da maneira "correta", o comportamento ideal, o ponto de vista adequado, dentre outros. A coisa à mostra é analisada de maneira satisfatória, pessoal, não como ela é. A situação é problemática.

Diante do conteúdo abordado, em saliência ao problema da ideia e a necessidade do cuidado, eis a crítica principal: é possível um direito sem lei?

\section{OS PRÉ-SOCRÁTICOS E MARTIN HEIDEGGER}

Para a plena compreensão do assunto tratado e os seus possíveis desdobramentos, é de suma importância entender os pensadores que dominam a principal base filosófica deste trabalho.

Ao abordar o pensamento de Martin Heidegger, busca-se, precisamente, o âmbito filosófico em destaque nos estudos contemporâneos. Um dos pontos interessantes é a caracterização como novidade e, além disso e justamente por isso, o apoio e a crítica são oferecidos de forma natural. Heidegger diz que "é, no entanto, mais salutar para o pensamento caminhar no estranho que instalar-se no óbvio" (apud MICHELAZZO, 1999, p. 13). Entretanto, por caminhar em um lugar desconhecido, a estranheza surge certamente. Sendo assim, a não aceitação ou o descrédito pelas pessoas é normal, até pela necessidade de utilizar como método, em um mundo que caminha ao pragmatismo, a instigação do pensamento ou reflexão.

Os meios de pensar ocidental, de acordo com Michelazzo (1999, p. 13), estão denominados como "pensamento metafísico e pensamento originário, ou ainda, pensamento que calcula ou pensamento que medita". O pensamento que tem conexão com os pré-socráticos é o meditante, mas, em vários momentos, é colocado de lado, ou seja, é esquecido. O raciocínio em destaque, utilizado pelos pré-socráticos, é um estudo que visa a aproximação do real, visível pela chamada "dualidade", inspirada na concomitância de ser e ente. Por mais que o presente estudo seja na linha heideggeriana, os pensamentos ocidentais mencionados, fomentam interessantes desdobramentos.

Heidegger é considerado e afamado como autor de difícil compreensão. Tem um tipo de abordagem fatigante e, nesse sentido, alguns conferem a impossibilidade de entendimento de 
seus escritos. Entretanto, surgem a autonomia e o acolhimento, os quais fazem conexão ao que Heidegger (1979, p. 144) disserta sobre o "manso rigor" ou a "rigorosa mansidão". Contudo, por mais dificultoso que possa parecer, independente da familiaridade, as percepções do autor fazem sentido se pensadas de maneira meditante.

De modo contrário ao quotidiano, o ser que Heidegger enumera não está, de maneira alguma, fora do pensamento. Michelazzo (1999, p. 18) afirma que este tal "pensar" é um modo de ser, ou seja, "um modo de estar na presença das coisas". Assim, vê-se um fenômeno que, simploriamente, refere-se à unidade de ser e ente, a chamada ligação em um "horizonte de totalidade e unidade". Sendo assim, o pensar e o ser se conectam e caminham na mesma trilha.

A filosofia ocidental, desde os gregos, busca e instiga a análise da essência daquilo que é, ou seja, a procura do ser. No entanto, essa busca ou investigação do ser é encontrada não no ser, mas no ente. Assim, como salienta Heidegger (2005, p. 17), a procura do ser do ente, do que faz o objeto ser o que "é", é desprovida de apreciação, isto é, a dita procura do ser inexiste, não é investigado em seu sentido original.

A verdade também é analisada pelos gregos como próximo do ser, com dependência à fundamentação do ser. Os gregos são os precursores do pensamento em destaque e deles vêm as melhores referências sobre o tema, atentando-se à união entre "pensar" e "ser". Tal unidade gera estranheza, mas, por dependência do homem enquanto ser, aos poucos se reorganiza por meio de um pensamento originário.

Alguns afirmam que o pensamento originário tem a finalidade de retornar à filosofia grega. Mas isso é um equívoco. Jacomini (2012, p. 41) diz que os pré-socráticos falavam a respeito do pensamento do ser, porém esse tal pensamento permanece hoje e há muito que refletir a seu respeito. Por mais que a maioria não dê o merecido reconhecimento, para a filosofia é o que detém maior dignidade.

\section{ENTE E SER}

O "ente" e o "ser" são atribuições existentes no pensamento de Heidegger, sendo imprescindível a distinção de seus âmbitos. O “ente" representa o âmbito ôntico e o "ser" o âmbito ontológico. O ôntico refere-se ao "existente, distinto do ontológico que se refere ao ser categorial, isto é, à essência ou natureza do existente" (ABBAGNANO, 1998, p. 727). Já a relação entre ente e ser, abordada no próprio título da obra de José Carlos Michelazzo, "Do um como princípio ao dois como unidade", significa que eles não se conectam em locais diferentes do real, mas há uma duplicidade como um todo. Tornam-se "o mesmo" e, nesse sentido, eles "são" em conjunto, não individualmente, pertencente a uma unidade. Leciona Loparic (1995, p. 22) que "diferentes, ser e ente não são um, sem, contudo, serem dois", mas são "o mesmo".

O ser das coisas deve, naturalmente, ser buscado, mesmo com a dificuldade de concluir o que é ser. Sabendo que ser é aquilo que é e que está mais próximo do homem do que dos entes é preciso aceitá-lo de forma simples. O ser se mostra sempre no ente, sendo nele o lugar próprio de 
sua abertura. "A essência do homem requer vir compreendida e fundada dentro da problemática do ser como o lugar que o ser reclama pela própria abertura", salientando suas possibilidades mais próprias (JACOMINI, 2012, p. 136).

Nesse sentido, tendo por base a mencionada proximidade do homem ao ser, há de se destacar que "a essência do homem consiste naquilo que ele é" (JACOMINI, 2012, p. 135). Nela, ele deve agregar o pensamento sobre a verdade do ser em conexão ao seu "ser-lançado", isto é, arremessado em direção ao existir do ser, por meio de seu reconhecimento. A ambiguidade entre ser e ente é, no mínimo, interessante. Não contém um tom negativo, porém relaciona-se ao modo de ser do homem. Jacomini (2012, p. 44) declara que essa questão "ente-ser" refere-se ao existir humano no aspecto daquilo que é (ente) e da "transposição do que "é" (ser).

Michelazzo (1999, p. 63) disserta que com o pensar metafísico e a aceleração da centralização do homem em meio real, surge, por consequência, o antropocentrismo. Entretanto, na análise moderna do ser, o nexo de relação entre a metafisica e o antropocentrismo faz sentido. O ponto central, iniciado por Platão, é o ser visto como idéa e, a partir disso, alguns elementos do pensamento, como precisão, cálculo e controle, usados no modo de apreensão do real, ou seja, do ente. Contudo, em qualquer lugar que o ente for colocado sob domínio da previsão e cálculo, o homem se põe em posição de destaque em relação ao real para, assim, diagnosticar a definição dos entes.

Já diante da análise fenomenológica, o estudo do "ser-no-mundo" pode ser direcionado à área jurídica, assim como para qualquer outra área, evidenciando não o jurista que somos, mas o jurista que queremos ser. Nesse sentido, Jacomini (2012, p. 98) diz:

Lançados no mundo, somos chamados, convocados e pressionados a sermos qualquer um dos outros. Durante toda a vida vivemos a impessoalidade como sendo quem nós mesmos somos. Vivendo querendo ser igual aos outros para podermos ser nós mesmos e, ao mesmo tempo, querendo ser diferentes para, também sermos nós mesmos. Essa identidade absoluta é insuportável e, quando aparece como alternativa ou desejo, desenvolve-se como uma doença, como um modo de ser deficiente. No máximo, o que é admitido como modo próprio de se cuidar do ser é um estilo pessoal, mas jamais um rompimento com os significados padrões.

Nesse aspecto, há uma necessidade de mudança no objeto de conhecimento, ou seja, deve dar um "passo de volta" ao ser e extinguir qualquer tentativa de formatação ou implantação de sua forma comportamental.

\section{ABERTURA DO SER: VERDADE E LIBERDADE}

A liberdade e a verdade, consoante Jacomini (2012, p. 68), fazem menção ao poder-ser do homem, ao poder-ser-no-mundo. Esse tal poder-ser é visualizado pelo Dasein (ser-aí) histórico no mundo, isto é, é a maneira pela qual o homem se corresponde com aquilo que vem ao seu encontro, 
com o que está presente e com o que já é passado.

Para que o homem conceda a verdade, deve haver consciência; sem ela, não fará sentido e não será real. Mas deve acompanhá-la, também, a responsabilidade e autoconsciência. Assim, é neste âmbito que se apreende o direito, como modo de ser do homem, aberto no mundo e sem objetividade: é o direito sob a verdade do ser (JACOMINI, 2008, p. 129).

De acordo Jacomini (2012, p. 80), a liberdade refere-se ao "ser-livre-e-aberto" para uma "solicitação". Esses termos, "livre" e "aberto", dependem do espaço e a base dessas ligações é uma circunstância, diferente do aspecto da lógica que é, para muitos, a única possibilidade de provar a verdade de algo. $\mathrm{O}$ espaço tem, assim, o caráter de acolhedor, pois concede a uma coisa o seu lugar, já que a condição de sua abertura se dá sempre com a presença de um ente (JACOMINI, 2012, p. 76).

Com o liame de "ser-livre-e-aberto", das delimitações do espaço pelo próprio acolhimento e do Dasein (ser-aí), fica evidente e necessário a análise dos fenômenos corporais, tendo o homem uma importância significativa na claridade do ser por ser seu guardião. O espaço implica nessa clareira, pertence a esse aberto que o homem mantém enquanto existente e que o ser se desoculta em sua verdade.

A "verdade", dentro da história da filosofia ocidental, distanciou-se da concepção grega de "não-velamento" e, posteriormente, veio a causar a perda, também, da essência da phýsis. Com Platão, o ser tornou-se apenas aquilo que é, sendo este, na realidade, o ente. Nesse "conflito", os gregos analisam a phýsis de maneira parcial, afetando diretamente a verdade do ser. Vale ressaltar, entretanto, que o fundamento da verdade é a liberdade (de abertura). Poggeler (1986, p. 193) diz que o pensamento grego se "obrigou" a mudar o olhar "e, por isso, se viram obrigados a esquecer, com uma determinada necessidade, a verdade de ser: a saber que o ser é antes de tudo o estar aberto e o ocultar".

A essência da verdade "é expressa na própria raiz da palavra alétheia (não ocultação)", afirma Jacomini (2012, p. 82). A “não ocultação" pode parecer ter um cunho negativo, mas referese apenas à aparição do ser. Essa definição implica, portanto, na origem do ser. Entretanto, cabe relatar a concepção de Platão a esse respeito, sendo ela diferente da heideggeriana ou da forma originária. Platão explicita sua concepção da verdade por meio do "mito da caverna", fazendo "referências em torno do papel da luz (ideia)", ou seja, semelhante ao que o sol faz na "constância de sua luminosidade" (vinculação), sendo importante que o homem dirija seu olhar naquilo que é iluminado e ele vê (JACOMINI, 2012, p. 82-83).

Já na visão mais originária, é entendido que o homem busque tal claridade no mostrar-se, no abrir-se da coisa. A verdade, juntamente com a liberdade de ser, faz parte dessa abertura.

O momento em que a verdade se rende fenomenologicamente explícita no conhecer é o momento em que se colhe a constituição da asserção como ser da própria coisa que é. Esta é verdadeira quando se verifica que é o próprio ente mesmo na afirmação. É a verificação da qual brota o ser-desocultante da asserção. Tal verificação consolida-se, assim, no ente, no qual o conhecer se justifica como 
verdadeiro (JACOMINI, 2012, p. 128).

Um ponto considerável são os estados do ânimo que estão no âmbito dos sentidos. Por meio desses estados é que as coisas adentram à realidade, isto é, tudo tem realidade por meio dos estados de ânimo. A esse respeito, vale ressaltar que os estados de ânimo são diferentes de emoções que, por sinal, não devem intrometer-se nas informações em relação ao mundo. Os estados de ânimo dão liberdade às coisas a serem o que são, descobrindo-as, primeiramente, num mundo circundante. Quando as coisas são abertas, o indivíduo descobre-se, então, como um ente que existe de fato e entretido com o mesmo mundo.

O existir, a região aberta do homem, sua estada ou, ainda, o homem habitado é designado de morada (ethos: ética). Nesse aspecto e enquanto existente, o homem deve buscar a verdade do ser como elemento original. O ser é, então, caracterizado como fundamento e a ética como “projeção do ser”. Essa verdade originária do ser não é pensada no âmbito jurídico atual, pois o direito, como modo de ser do homem, há muito não é assim pensado (JACOMINI, 2012, p. 88-89).

Portanto, o ente homem, constituído de suas particularidades, se faz pertinente a tal análise. Com isso, a interpretação do eu (si mesmo) é um primeiro passo que deve ser dado pelo ser humano. Mas requer cuidado por ser meramente um passo inicial (ideológico). O cuidado já se faz necessário pelo corriqueiro fato do eu ser visto de uma forma pluralizada. No cotidiano, o homem não é visto em sua singularidade, mas pelas qualificações gerais, pelo padrão. Isso acontece, por exemplo, no campo jurídico, onde se preza pela justiça, por aquilo que é justo.

O direito, assim, na plenitude, não tem sua origem no desocultamento. Todo direito autêntico aparece, portanto, afeto de ser ainda não direito. A presença do não direito no direito deve afirmar-se na sua fase de existência, pois a salvação do homem não está na obra, mas sim na sua função de manter o homem na abertura da verdade do ser (JACOMINI, 2012, p. 122).

No mundo atual e a partir dessas pontuações, seria possível afirmar que a lei é capaz de definir o direito por meio da verdade do ser? É facilmente compreensível que não e, de forma semelhante, a justiça também não é. Ao contrário e apenas com o pensamento originário, possivelmente a “justiça” permitirá que a verdade, essencialmente, seja um resultado.

\section{MÉTODO FENOMENOLÓGICO}

A observação e a reflexão raramente existem de maneira profunda. Quando alguém procura refletir, em sua maior parte, é superficialmente. Com isso, o próprio mundo em que o ser humano está não é compreendido. Afinal, o homem sabe o que acontece no seu dia-a-dia? É pertinente destacar o método fenomenológico do direito, contemplando a importância do ouvir, falar e, principalmente, o pensar silencioso, que se conecta à corporeidade.

A compreensão, dentro da analise fenomenológica, é vista como possibilidade. Nesse 
sentido, há uma coincidência entre ser e aparecer, ser-no-mundo e ser-com-os-outros. Diante dos modos-de-ser-no-mundo (existencial), como formas de ser e se manifestar, é preciso enfatizar a relação entre o ente e o ser (o mesmo), pois o ser não é dado como ente, no sentido definitivo, mas como um feixe de possibilidade. Contudo, o ser-no-mundo, por meio do ato humano, não compõe uma individualidade em seu desdobramento, pois o olhar humano não é meramente individual, mas coexistente (CRITELLI, 2006, p. 73).

Assim, a coexistência entre ser e ente é condição fundante de toda possibilidade de ser. Neste sentido, Jacomini (2012, p. 158) afirma:

\begin{abstract}
É desde um certo e refletivo ser-no-mundo-com-os-outros que o fenômeno recebe sua possibilidade de ser, sua possibilidade de realidade. Com isso, quando o ente aparece, ele, de algum modo, já foi trabalhado como real, ou seja, o aparecer dos entes em seu ser supõe que aquilo que se mostra já tenha a sua realidade garantida e promulgada. A percepção de algo depende de esse algo ter sido resultado de um movimento de realização, movimento simultâneo temporal e existencial.
\end{abstract}

Pensar e ser é, também, uma unidade fenomenológica e implica no movimento de realização existencial. Trata-se de maneira de pensar circulante, como forma de pensar originariamente, ou seja, um recuo à origem. Seria, basicamente, um avanço à análise que caminha como um "movimento espiral descendente". "O pensamento em círculo não desemboca propriamente em conclusões, mas em questões que abrem novas questões que se originam sucessivamente." (JACOMINI, 2012, p. 143). Enfim, como visto anteriormente, trata-se do pensamento meditante, aquele pautado pela cautela, aquele que investiga o que as coisas são em sua essência. Pensar não é simplesmente o cálculo de ações com vistas a uma atualização da situação presente, mas o desocultamento com a liberdade de ser e a verdade reveladora. "Pensar e ser estão unidas no sentido do que tende a opor-se, isto é, são o mesmo como pertencentes um ao outro num único conjunto.” (HEIDEGGER, 1969, p. 162).

É possível, portanto, a seguinte indagação: de que maneira prática se pode efetivar o direito a partir desse pensamento? Por meio da hermenêutica se pode trabalhar pensamentos conectivos e essenciais, ou seja, meditantes. $\mathrm{O}$ ente e o ser habitam uma unidade e, somente assim, haverá a possibilidade de ver o que são e como são os seres enquanto seres. No campo jurídico, deve deixar o homem ver seu direito enquanto próprio modo-de-ser. Também requer "cuidado", pois, para ser compreendido naquilo que ele é e como é, não depende, necessariamente, da existência de lei positiva. Porém, se ela existe, seja ela também tomada como ser, mas como um ente que orienta na busca pelo ser-direito.

Por meio do círculo hermenêutico é possível a apreensão do método fenomenológico, com fulcro no caminho investigativo que contempla o método e o objeto (HEIDEGGER, 2005, p. 56). Esse círculo demonstra o caminho percorrido pelo pensamento originário, ou seja, o caminho entre a borda e o centro. Aqui, salienta-se a necessidade do meditar do homem para aceitação da sua natureza contingente. Isso se faz razão de sua existência e faz surgir a ele mesmo o próprio 
fundamento, principalmente no que se refere ao direito.

Portanto, não é possível evitar o círculo hermenêutico, motivo fundado pelo próprio pertencer do ser à aproximação do homem em sua angústia pelo direito. Frente às obscuridades, na maioria das vezes, o direito não é trazido à luz por um olhar compreensivo. $\mathrm{Na}$ análise atual do direito, o modo fenomênico é inutilizado, pois usa-se da metafísica platônica para confundir o modo-de-ser direito com o ente-lei. Com o modo originário, existiria a possibilidade de as coisas serem o que elas são e como são. Mas tal inutilização é existente pelo esquecimento do ser.

O homem, de modo geral, tem a condição de perceber a manifestação própria e seu desdobramento. Por exemplo, incomoda-nos os cães do vizinho porque admitimos o comportamento barulhento deles. Se deixássemos os cães serem, inclusive, cães que latem, eles não nos perturbariam e aborreceriam. Por não correspondermos ao ser dos cães, somos solicitados por ele. Já no caso de um criminoso, ele é o solicitado, é nele a falta de relação livre do ser humano com aquilo que o encontra, o apropriar-se destas relações e deixar-ser solicitado por elas (JACOMINI, 2012, p. 150).

Contudo, dada a importância da análise fenomenológica e os demais desdobramentos, atribui-se pertinência ao pensar e, simplesmente, ser. A relação entre o olhar e a própria coisa é trocada pela coisa em si mesma, gerando ideias inconsistentes e que beneficiam apenas alguns, como ocorrem em algumas leis, por exemplo.

\section{LINGUAGEM}

Filosoficamente, a linguagem é um dos âmbitos mais complexos por navegar nas águas do relacionamento entre o homem e as coisas. Nesse aspecto, o homem, por ter a linguagem, não é meramente algo com vida, mas um "ex-sistente". Heidegger (2005, p. 42) diz que se homem for capaz de pensar a verdade do ser, o mesmo estará pensando a partir da "ex-sistência".

Conotativamente, a linguagem faz parte de uma estrutura para construir a morada do ser. Nesse sentido, Jacomini (2012, p. 120) afirma que:

No ministério da linguagem, no qual se deve reunir toda a reflexão hermenêutica, resta o fenômeno mais digno de ser pensado e interrogado. A linguagem seria menos distópica se a gramática e a lógica não se lhe impusessem sempre, restringindo o que pode ser dito e pensado. Evitar esta restrição libertaria os seres humanos para outras possibilidades além das prescritas pelas relações técnicas.

Quando o direito é analisado em consonância com a questão da linguagem, a abertura do ser compõe um primeiro destaque, pois "o homem está cada vez mais distante de si mesmo", afirma Jacomini (2012, p. 109). Com a linguagem e a essência do homem, o modo-de-ser-direito se abre e "a essência do edificar" aparece. Essa essência é, segundo Jacomini (2012, p. 115), o executar, no sentido de executar a relação do ser à essência do homem. Tal movimento implica na questão da verdade do ser, ou seja, na abertura e compreensão do ser. Contudo, a declaração da verdade não é 
feita de modo lógico, metodológico e conceitual, mas por meio dos pontos abordados inicialmente pelo viés fenomenológico, como o habitar existencial e outros.

Na filosofia do direito, a condição do eu de reconhecer a si mesmo comporta a possibilidade do homem de retirar-se da habitualidade. Essa o envolve e o consuma entre leis e normas sem questionar sobre o sentido do modo-de-serdireito e sem mostrar o direito do homem na sua irredutibilidade ao direito positivo. O conteúdo das normas que respeitam tal reconhecimento e sancionam sua inibição tem a estrutura da juridicidade. Pressupõe-se que é só do homem o poder de conceber a verdade e, portanto, adquirir o conhecimento daquilo que é justo, verdadeiro (JACOMINI, 2012, p. 116).

A linguagem pode mostrar informações singelas do homem, mas, ao mesmo tempo, velar a abertura do ser. É o paradoxo da linguagem, pois, no momento em que ela consegue expressar o ente, ela tende a ocultar o ser. Nesse sentido, essa linguagem vista como fenômeno é objeto da hermenêutica analítica.

\section{O MODO-DE-SER-DIREITO E A LEI}

Diante de conceitos e questionamentos naturais do pensamento, podemos chegar a determinadas proposições. Ao apresentar uma premissa que diz que é possível um direito sem lei, surge uma análise inicial teórica e, também, prática: como o estudo do ser faria sentido na sociedade ou na atividade jurídica? Sabe-se que todo o conteúdo é complexo e sempre contém algo que depende do cuidado e do olhar hermenêutico para ser compreendido. Entretanto, tal conhecimento não satisfaz o mencionado, pois ele não é teórico e nem prático, já que acontece e se realiza antes deste momento. Com base em Heidegger (2005, p. 76), o pensamento "é, na medida em que é, a lembrança do ser e nada além disso".

Muitas vezes, no direito atual, o ditado "os meios explicam os fins" é utilizado, mas erroneamente. Existe um procedimento padrão para chegar a uma “soluçãojusta"? Há procedimentos legais que acabam por prejudicar as pessoas, seja por não alcançar uma solução ou por determinar uma solução injusta. Será que a formalidade e o positivismo jurídico são as melhores opções para resolver as lides?

A filosofia do direito não surge com a finalidade de deixar as situações fáceis e imediatas, por mais que tenha fundamentos pela Justiça. Seria uma utopia dizer que a filosofia iria aprimorar a Justiça. Por outro lado, há uma noção de inutilidade da filosofia, infelizmente, porque o mundo atual quer respostas prontas e formatadas. Não sabe ter "paciência" diante da "angústia", o que é questionável já que é exatamente essa angústia que colocará critérios de possibilidades para o futuro. Contudo, a intenção da filosofia é mostrar que tais possibilidades são complexas em uma totalidade e não facilitar as coisas com a observação apenas dos meios.

O direito, tema principal do trabalho, está incluído na análise dos fenômenos corporais. Nesse sentido, “o Dasein (ser-aí) deve ser visto sempre como ser-no-mundo [...], como um estar na 
clareira [...], como desocultamento para aquilo que vem ao encontro.” (JACOMINI, 2012, p. 77). É preciso destacar que esses fenômenos não são explicáveis, visto a impossibilidade de se chegar à sua essência. "O direito, assim, deve ser tratado sempre a partir do ser- no-mundo e não apenas da legalidade de um fato." (JACOMINI, 2012, p. 77).

Usar um pensamento que se limita a algo definido é um equívoco, pois o objeto se constitui desde a sua origem. $\mathrm{O}$ direito atual sugere esse equívoco ao utilizar-se de padrões e formatos calculados para identificar o "real". Nesse sentido, o ser é esquecido e esse direito que se sustenta com um conceito ou noção está indo a um caminho perigoso.

Ao contrário, "o pensar essencial consiste em colocar a questão da origem e do nascer do ser." (JACOMINI, 2012, p. 26). Com base na temporalidade que lhe é própria e a predisposição para sua verdade, o modo-de-ser-direito deve ser desolcultado nos tribunais, por meio de um pensamento originário, sereno e meditante. A análise do modo-de-ser-direito advém de questionamentos ou indagações e, nesse sentido, essa investigação deve se guiar pelo próprio homem em seu estarsendo-no-mundo. Assim, surge a possibilidade de desocultamento do direito, o que ele é e como é, pois, antes da sentença final, há que se ter uma percepção de que o direito "é".

Por mais que o trabalho esteja sendo conduzido pela análise da possibilidade de um direito sem lei, não há que se confundir com eliminação ou condenação da lei. A lei tem a sua devida importância, porém não é ela que define o direito. A ideia normativa ou positivada não traz um olhar ao ser e, nesse sentido, a possibilidade de leis inautênticas. Contudo, espera-se que a lei tenha um olhar ao ser e, assim, a verdade do direito, afinal a Justiça preza por leis dessa natureza.

O direito é, certamente, um modo-de-ser, o qual garante o ser de outro modo-deser. A forma terrena da verdade é a qualidade da relação humana, possibilitando ao homem retirar-se da habitualidade que o envolve e o consuma, sem interrogar-se sobre o sentido do direito e sem mostrar o direito do homem na sua irredutibilidade às leis e às normas (JACOMINI, 2012, p. 47).

Heidegger (2005, p. 83) apresenta um questionamento que se conecta ao nosso principal assunto jurídico: "Qual a lei do seu agir?" Esse questionamento tem uma profundidade impressionante. É sabido que a nossa intenção é demonstrar a possibilidade de um direito sem lei, e esse questionamento apresentado é semelhante ao nosso viés jurídico: afinal, qual é a lei? Poderíamos falar algumas possibilidades, mas preferimos responder com o que nos conecta: simplesmente, pense. Heidegger (2005, p. 83) diz: que "na presente indigência do mundo, é necessário menos Filosofia, mas mais desvelo do pensar; menos literatura, e mais cultivo da letra".

Jacomini (2012, p. 36) pontua um problema filosófico significativo: “[...] para determinadas linhas filosóficas, a experiência cotidiana e concreta já é aquilo que é o verdadeiro; para outras, a existência humana concreta e imediata é instável, confusa e superficial."

Ao aprendermos as premissas estudadas, principalmente o modo de ser do homem e o modo de ser acolhido também ao direito, há uma indagação: Hoje, as leis são apoiadas em um modo de ser do homem no mundo? A resposta a esse questionamento é "não" e, em razão disso, há 
motivação para a realização do presente trabalho e para lutar, com cuidado e atenção, a fim de que a mudança necessária seja, essencialmente, presente. Nesse aspecto, em um tom complementar à indagação, Jacomini (2012, p. 107) salienta:

A lei deve ter significado e ser originada de um modo-de-ser-no- mundo. E é à existência humana que sua significação pertence. Nunca às coisas nelas mesmas. Os significados das coisas apenas "são", à medida que mantém e estabelecem a ligação dos homens entre si e com o mundo. O ser de tudo o que há está no estarsendo-dos-homens-no-mundo.

Para que o objeto do pensamento seja real, "tudo depende do fato de a verdade do ser atingir a linguagem e de o pensar conseguir esta linguagem [...]. Se um dia o homem tivesse a sorte de realizar um tal pensar, não aconteceria uma desgraça" (HEIDEGGER, 2005, p. 53-54). No entanto, permanecemos em "silêncio".

\section{JUSTIÇA}

Falar sobre justiça, no Brasil, evidencia a atuação do Poder Judiciário. Aliás, é, principalmente, aquele que se mantém distante da verdade do direito. Nesse sentido, pode-se dizer que a sociedade está acostumada com um mecanismo familiarizado no atalho do silêncio, calcando-se, ideologicamente, que apenas este sistema é justo.

Neste cerne, o próprio pensar fenomenológico traz uma possiblidade de justiça a se pensar, diferente da usual ou habitual. Sabe-se que o modelo positivista usado atualmente é deficiente e que, cada vez mais, sentencia injustiças. Diante deste cenário, é necessário refletir sobre a realidade humana porque, se persistir com a forma existente, aquela que não pensa no ser, haverá mais e mais problemas ao invés de soluções.

A Justiça que se preza pela busca da verdade do direito não se encerra apenas na lei. Afinal, direitos são garantidos por sermos humanos, não por existir direitos humanos prescritos em lei. Atualmente, o que mais se aproxima que conecta ao pensamento originário é a Mediação e a Arbitragem, instrumentos que independem de lei. Não se utilizam apenas da lei, mas também de princípios gerais do direito e de julgamento por equidade.

"Enquanto na Justiça comum o Juiz é obrigado a fundamentar sua decisão na lei, na Arbitragem, a critérios das partes, o julgamento pode ser por equidade, nos princípios gerais do direito, nos usos e costumes [...].” (CMABQ, [1996?]).

Vivemos um direito e uma justiça que se limitam em ideias e cálculos. Nestes, a jurisprudência confirma o já "formatado" para a definição da realidade e identificação do direito. O homem não é mais observado, pois é a razão posta que o enquadra. Contudo, inexiste a verdade jurídica nessa posição ideológica ou positivista.

No ordenamento pátrio, cuja visão é a positivista, os magistrados têm a função de julgar lides com base na lei. São esses magistrados que devem dizer o direito e serem justos. Essas ideias 
são interessantes, mas divergentes do pensar fenomenológico. Diante da fenomenologia, Jacomini (2012, p. 131) mostra a relação jurídica que se constitui:

É dessa maneira, também, o modo-de-ser-direito na relação dialógica, na autêntica relação jurídica entre o "eu" (ente), o "outro-do-eu" (ser) e o juiz (testemunho). Aqui, o juiz é o testemunho qualificado do direito, ou seja, de um modo-de-ser que garante o ser dos outros-modos-de-ser.

O mundo sendo visto como ser comum a todos, é possível configurar o testemunho. Por meio disso, "o eu pode ser o que é e como é". Tais modos, abertos no mundo, contemplam significados e a visão da singularidade (o eu) em sua realidade. Isso se faz presente por meio do testemunho do homem e não como é idealizado pela visão positivista.

No Direito Penal, por exemplo, deve-se indagar, primeiramente, a pessoa e o seu comportamento. Perguntas que indagam o "por quê" buscam pela abertura do ser e, portanto, devem ser feitas de primeiro plano. A ideia de penalizar alguém apenas por estar prescrito em lei não é um caminho adequado ao senso de Justiça. Enquanto o reconhecimento do ser não for priorizado pela justiça, existirão desgraças.

Por fim, a própria indagação do que é justiça nos faz refletir, mas, além disso, possivelmente, podemos concluir que métodos usados com formalismos em excesso e alongamentos não são essenciais. Ao contrário, a justiça constitui-se da obra do homem em menter-se aberto na relação de reconhecimento de si mesmo e do outro. Ela incide sobre esta obra e alimenta-se, em toda sua presença, da plenitude do direito, isto é, é um modo da projeção iluminadora da verdade, é um modo de revelar a verdade do modo-de-ser-direito do ser humano. Trata-se de um modo essencial de revelação no qual o indivíduo permite que o seu modo-de-ser-direito, original, tornese manifesto e de forma explícita.

\section{CONCLUSÃO}

Em face do exposto, fica evidenciado que a lei, por estar prescrita, não é um freio para que o direito seja indagado a uma pessoa. Há que se pensar em possibilidades cujo resultado gere a menor lesividade aos envolvidos, podendo-se afirmar que a melhor maneira de solucionar um conflito, por exemplo, é a existência de direitos por ser humano de direitos, e não por ter um livro ou documento que conste a respeito dos "Direitos Humanos", ou seja, a busca ao mais próximo da origem e da essência do homem.

Dada a diferença ontológica entre o ser e o ente na busca pela verdade do modo-de-serdireito, tem-se uma possibilidade de exploração de fronteiras desconhecidas da sapiência. Sabese que o direito e outros aspectos interpretativos, essencialmente, detém a complexidade. Nesse sentido, acredita-se que, com a análise fenomenológica e a serenidade, torna-se possível minimizar a angústia, nos aproximando destes âmbitos profundos e difíceis.

O direito é um modo-de-ser original, aberto no mundo sem precedentes, sem objetividade, 
com importância própria, livre. Antes de ser um direito positivo, ele já é um modo-de-ser autêntico, verídico, justo, originado da verdade de ser do ser humano.

Portanto, todo o conteúdo apresentado anteriormente pode trazer benefícios insofismáveis ao ser humano e à sociedade, de maneira a constituirmos colaborativamente uma comunidade pensante e desprendendo-se de ideias que formatam o homem, o seu modo de ser e, consequentemente, seu existir.

\section{REFERÊNCIAS}

ABBAGNANO, Nicola. Dicionário de filosofia. São Paulo: Martins Fontes, 1998.

CMABQ - CÂMARA DE MEDIAÇÃO E ARBITRAGEM DE BRUSQUE. Como funciona uma câmara de mediação e arbitragem. Brusque: CMABQ, [1996?]. Disponível em: http:// www.arbitragembrusque.com.br/arquivos/190. Acesso em: 15 jul. 2018.

CRITELLI, Dulce Mara. Analítica do sentido: uma aproximação e interpretação do real de orientação fenomenológica. São Paulo: Malheiros, 2006.

HEIDEGGER, Martin. Carta sobre o humanismo. São Paulo: Centauro, 2005.

HEIDEGGER, Martin. Introdução à metafísica. Rio de Janeiro: Tempo Brasileiro, 1969.

HEIDEGGER, Martin. Sobre a essência da verdade. São Paulo: Abril Cultural, 1979. (Os Pensadores).

JACOMINI, Alessandro. Hermenêutica do direito e o círculo da compreensão. Jundiaí: Paco Editorial, 2012.

JACOMINI, Alessandro. O direito sob a verdade do ser. Curitiba: Juruá, 2008.

LOPARIC, Zeljko. Ética e finitude. São Paulo: EDUC, 1995.

MICHELAZZO, José Carlos. Do um como princípio ao dois como unidade: Heidegger e a reconstrução ontológica do real. São Paulo: FAPESP: Annablume, 1999.

POGGELER, Otto. El caminho del pensar de Martin Heidegger. Madrid: Alianza Almedina, 1986.

Como citar: MESQUITA, Lucas Daniel Vieira; JACOMINI, Alessandro. Direito sem lei: um modo-de-ser do ser humano. Revista do Direito Público, Londrina, v. 15, n. 1, p. 85-99, abr. 2020. DOI: $10.5433 / 24157-108104-1.2020 v 15 n 1 p$. 85. ISSN: $1980-511 X$

Recebido em: 09/12/2018

Aprovado em: 06/05/2019 